tion of such measures without sufficient notice, and at the same time to discourage their adoption without sufficient time having been afforded for reflection when they are introduced. The passing of any measure likely to affect materially the interests of the Association, will not be hastily acceded to by a general meeting, if, by postponing it for a time, it is likely that the Association will derive the advantage of ascertaining the views of the members at large. By the arrangements now adopted, this is readily accomplished in regard to all matters brought forward by the council. The proposed report is always circulated amongst all the members of the council, and consequently in every place where the association possesses influence, and the branches have thus the opportunity afforded them of expressing their opinion on the questions intended to be brought forward at the general meeting. If this provision be called for and acted upon with respect to measures, the bearing of which has been well considered by those who are most intimately acquainted with the affairs of the association, it becomes far more necessary in respect to such as may be brought forward without having previously received the advantage of such consideration. The giving efficiency and support to those branch associations which already exist, and encouragement to the formation of new ones, wherever a sufficient number of members reside, should, therefore, as it appears to us, occupy the attention of the council. In many other respects,-for instance, in affording occasions to bring the members of the profession into friendly intercourse with each other, in facilitating the collecting and communication of valuable local information, in conducing to the rubbing off the rust of seclusion so apt to be acquired by those who are thrown entirely upon their own resources, these more local institutions can scarcely be too highly appreciated.

\section{ROYAL MEDICAL AND CHIRURGICAL SOCIETY.}

Tuesday, July 6, 1841.

Dr. WhLliams, President.

ON ABSORPTION AND REGENERATION OP THE NECK OF THE THIGH-BONE AFTER FRACTURE WITHIN THE CAPSULAR LIGAMENT. BY W. W. BEEVER, ESQ., OF MANCHESTER. COMMUNICATED BY MR. PARTRIDGE.

THE patient, a woman, aged 73, lived nearly four years after the accident. On examination no vorige of the neck remained, except a triangular portion of the under surface, three-fourths of an inch in length, which, from the obliquity of the fracture, had not been detached from the head. This was articulated by a distinct capsule to a second fragment jutting out from the shaft, and firmly united to it, immediately anterior to the lesser trochanter. This adventitious joint, and a band of ligamentous structure extending from the posterior edge of the head to the capsular ligament, formed the only connexion between the head and body of the femur. From the large quantity of callus thrown out by the trochanter and head of the bone, the author infers the possibility of bony union being effected.

CASE OF ANEURISM OF THE RIGHT SUBCLAVIAN ARTERY, IN WHICH THAT VESSEI, WAS TIED INTERNAL TO THE SCALENUS MUSCLE. BY RICHARD PARTRIDGE, F.R.S., PROFESSOR OF ANATOMY IN KING'S COLLEGE, AND SURGEON TO KING'' COLLEGE HOSPITAL.

The patient, David Hickiman, was a married man, 38 years of age, muscular, of a sallow complexion, and had lived rather an intemperate life. His occupation was that of a grinder and polisher of heavy iron plates; an employment requiring great muscular exertion of the arms. He had been the subject of several slight rheumatic attacks, and once, about a year before his admission into King's College Hospital, he had what he called a fever, which laid him up for six weeks, and was attended with cough and pains about the upper part of the chest. After this illness he was always subject to pains below the clavicle, which were brought on by any unusual muscular exertion. In August, 1840, about five months before admission into the hospital, he began to experience pains along the right side of the neck and over the corresponding shoulder, with numbness of the arm, and an increasing want of muscular power in the whole limb.

About a month after the appearance of these symptoms, a pulsating tumor showed itself above the right clavicle; and as this enlarged, the numbness of the arm and the pains in the neck and shoulder became worse, so that, finally, the man was obliged to abandon his employment.

Feb. 1, 1841. - Hickiman was admitted into King's College Hospital. He had then an aneurism of the right subclavian artery, extending from the outer border of the anterior scalenus, which it appeared to overlap, downwards, behind the clavicle into the axilla as far as the lesser pectoral muscle. The tumor was slightly compressible, and appeared to contain fluid blood. Upon a careful examination, the right common carotid and subclavian internal to the scalenus seemed healthy; the arteria innominata was thought to be enlarged, as well as the arch of the aorta; it could not be ascertained that they were otherwise diseased. No disease could be detected in the heart or lungs, though there was pain on percussion beneath the right clavicle. The pulse at both wrists was about 80 , full, soft, and regular.

The right upper extremity was somewhat wasted comparatively with the opposite limb. The patient's rest was at night very much disturbed by the pains and numbness of the arm.

The patient was placed in bed at perfect rest, with low diet and occasional aperients.

The pains in the limb were relieved by wrapping it in flannel; and this, with an occasional opiate at night, procured him comfortable sleep.

The patient was bled from the left arm after his admission four times, at intervals of three or four 
days. After these venesections the pulse always became lower, and they appeared to have the effect of diminishing the pains in the arm and shoulder.

Feb. 20. Mr. Partridge put a ligature on the subclavian artery internal to the scalenus.

An incision was made between three and four inches in length along the clavicle to the centre of the upper border of the sternum, dividing the skin and platysma; the sternal origin and part of the clavicular fibres of the sterno-mastoideus were next exposed and divided, and then a small anterior jugular vein which crossed the incision; afterwards the sterno-hyoid and sterno-thyroid muscles were cut across, and after some careful dissection the artery was exposed, lying very deeply at the bottom of the wound. The vessel was large, but otherwise healthy; the internal jugular vein and nervus vagus were drawn to the outer side of the wound, and a strong thread ligature was passed around the artery by means of a common aneurism needle; care being taken to avoid wounding the pleura, which lay immediately underneath the vessel. Upon securing the ligature, pulsation in the tumor and at the wrist ceased.

Soon after, being placed in bed, the man felt sick, and vomited.

In the evening, about four ounces of blood were lost from the small anterior jugular vein, which had been divided during the operation : it was secured with a ligature. At night the patient complained of pain at the pit of the stomach; this was relieved by an opiate draught, and he dozed quietly until the morning, when the pain at the stomach returned severely, accompanied by thirst: it yielded to venesection, but after a few hours recurred, and was not, as before, relieved by bleeding. The thirst also returned, and pain was felt along the right side of the sternum, and the pulse and respiration were quickened. A very faint pulsation was felt at the right wrist, and continued until the patient's death. The symptoms increasing day by day, the patient soon became exhausted; his face was pale, and covered with a clammy sweat; his look became anxious; the pulse small, and very rapid; and the respiration quicker. The thirst was excessive; but all attempts to relieve it by fluids, produced intense pain at the scrobiculus cordis. Temporary relief was afforded by leeches and mustard-poultices, applied to the chest and pit of the stomach, but the pains soon returned. On the 24th of February (at 11 A.M.) the fourth day after the operation, the man died.

On the 26th, the body was examined as carefully as could be done at the patient's house, where it had been removed by the friends. The aneurism was found to extend from the outer edge of the scalenus to the lesser pectoral muscle; internally, the sac turned over the outer border of the scalenus, and overlapped it. It contained coagulated blood, but no fibrinous deposits, and its coats in some places were exceedingly attenuated. It would have been impossible to have placed a ligature on the artery, either on the outer side or behind the scalenus. The ligature was found on the artery, mid-way between its origin and the inner border of the scalenus anticus. The nervus vagus, the recurrent nerve, and the pleura, were uninjured.

In the chest, on both sides, were found old adhesions, between the pleura costalis and pulmona- lis, with serum in the cavities of these membranes, but especially on the right side of the chest, where the pulmonary portion of the pleura was slightly coated with recent lymph. There were tubercles, in a quiet state however, scattered through the upper lobes of both lungs. A small quantity of serum was found in the pericardium, and its inner surface was coated with a thin layer of recent lymph. The heart, arch of the aorta, arteria innominata, and both common carotids, though rather larger than natural, were healthy. Three small deposits of pus were found in the cellular tissue near the wound, and along the anterior mediastinum: they were unconnected with each other. The wound itself looked healthy. No clot existed, either in the subclavian artery or in the vessels springing from it, None of the veins were inflamed. The stomach appeared quite healthy.

The author, after detailing the case, states his reasons for putting a ligature on the subclavian artery, internal to the scalenus, in preference to any other operation. He next proceeds to take a review of the symptoms, and the probable cause of death, and compares them with those which were observed in other cases in which this operation had been performed.

CASE OF FATAL ENCEPHALITIS, WITH HEMIPLEGIA, IMMEDIATELY EXCITED BY CANTHARIDES, IN CONSEQUENCE OF INTENSE PREDISPOSITION FROM BASILAR AND INTERNAL CAROTID ANEURISMS. BY P. W. KINGSTON, M.D., PHYSICIAN TO THE ST. JAMES'S AND ST. GEORGE'S DISPENSARY.

James Hullah, between fifteen and sixteen years of age, shoemaker, admitted Dr. Kingston's patient at the dispensary, Oct. 17, 1836.

He has for three years and a half had a throbbing tumor at the right side of the neck, which has gradually reached the size of two-thirds of an orange, but has otherwise been considered strong, and free from ailment, till this morning, when he was suddenly seized with vomiting and with numbness, and almost total loss of power of the trunk, the right arm and leg, the right side of the mouth, and the tongue. Pulse 80 ; bowels confined for four days. He died in thirty-eight hours and a half : during this period the urine was almost entirely suppressed; the vomiting continued frequent; there was occasional suspension of respiration, followed by spasm of the larynx; he lost, after a time, the power of deglutition, and became by degrees completely comatose.

It was ascertained that the night before the seizure he had taken some Spanish fly in an apple. The body was examined sixteen hours after death. Patches of the mucous membrane of the stomach presented a degree of redness, softness, and elevation, which contrasted strongly with the appearance of the adjacent parts. The spleen was softened. The kidneys were much congested, and their cortical portions softened : the pelvis of the right was flled with nearly an opaque, white, flaky fluid, of creamy consistence. The mucous membrane of nearly half the bladder was deeply reddened and much softened. There was a large aneurismal dilatation of the right internal carotid artery; and one of the basilar artery, of the size of a moderate walnut, which appears to have formed gradually, and without rupture of its tunics. The pons Varolii had become flattened by the preasure 
of the basilar aneurism, and was much softened for the depth of a quarter of an inch. The right lateral ventricle contained an ounce of limpid serum, the left none.

In his evidence given at the coroner's inquest in this case, the author commented upon the fact, that the fatal termination immediately occasioned by cantharides would not have resulted from so small a dose, but for the predisposing causes here noticed. And he points out the application of which this kind of reasoning is capable, in many trials for murder.

\section{PROVINCIAL MEDICAL AND SURGICAL ASSOCIATION.}

\section{SHROPSHIRE AND NORTH WALES BRANCH.}

ThE Annual Meeting of this Society took place, on Thursday forenoon, at tbe Lion Hotel. The President, Dr. Parker, of Overton, was in the chair. The other members of the Society present were-Rice Wynne, Esq., Dr. Jeffreys, (Liverpool,) Dr. H. Johnson, Mr. E. Gwynne, (Wem, Messrs. Webb, (Ketley Bank,) Mr. Watson, (Ellesmere,) Mr. Wilding, (Church Stretton,) Mr. Hickman, (Brockton,) Dr. Marsh, Mr. R. Cartwright, Mr. J. N. Heathcote, Mr. J. Y. Arrowsmith, Mr. Darkin, and Dr. Ward.

On taking the chair, Dr. Parker expressed his regret that the attendance of members was not more numerous, and attributed it to the non-adherence to the original day fixed for the meeting.

Dr. Jeffreys regretted the small attendance on the present occasion. But he considered that, in all probability, circumstances which might not occur again had share in causing this.-(Hear.) The Elections had materially interfered in this manner with their recent Lancashire meeting.

Mr. Lee, of Ellesmere, Mr. Thomas Gwynne, and Mr. Richard Wilding, were admitted members.

\section{PRESIDENT'S ADDRESS.}

The president then said that it only remained for him to make a few remarks, -and before he did so, he was bound to allude to the difference between the reception the members had from him and from last year's president, Mr. Rice Wynne. The splendid hospitality which that gentleman had exercised on that occasion, was such as to preclude any attempt at imitation. Nor, indeed, could it be a rule to guide his successors. The president then read his address, which contained a brief and clear history of the state of the medical profession under the control of the corporations, as originally chartered by Henry VIII. down to the present time; alluding to the anomalies of their primary institution, which had continued, under all the changes of society, to the present day. He noticed some views projected for the removal of these anomalies, by such modifications in the institutions as the wants of the profession and the case required. He stated his views upon professional education, as alike important to the public and practitioners. He then alluded to, and lamented, the prevalence of quackery, which he described as an evil springing from and fostered by popular ignorance, and, like superstition, to be best corrected by more extensive knowledge and enlightened views. Dr. Parker then spoke of the evils arising to the public from the want of a responsible Board of $\mathbf{H e a l t h}$, and a Medical Police to superintend and inquire into all causes which may influence health-such as sewerage, ventilation, \&c. He noticed that the inequalities of health between the richer and poorer sections of a people might be somewhat reduced by a judicious legislation, and he commented, with much force and at some length, upon the evils arising to the public from the New Poor-law regulations as to medico-parochial duties, - he said that in the case of vaccination this was especially obvious, as that would be much retarded by such injudicious interference. He considered that all the evils were remediable by an improvement in the machinery of the existing bodies, without their entire subversion,-the force of public opinion would be of more avail than legal enactments. Dr. Parker said that he had now to resign his office into the hands of his successor. Accordingly,

Mr. E. Gwynne, President for 1841-2, then took the chair. He said that he was fully aware of his deficiencies, but he entered into the discharge of the duties which now devolved on him with a desire to execute them faithfully. He avowed himself a Medical Reformer, but had never yet learned by what means medical reform was to have been effected, so as to conduce to the dignity of the profession and the adrantage of the public. He thought that legal enactments might place the profession in a worse position than they now occupied. The reform committee, before any measure was proposed to parliament, should lay its details before the profession at large, and have them fully diseussed. A measure relative to druggists had lately been introduced, but this was only "throwing a tub to the whale."-(Hear.) He did not see how druggists dispensing medicines could interfere with or injure the profession. If a person wanted a black draught, he could get it as good at the druggist's as if he had occupied ten minutes of a medical man's time in stating his case. Empiricism could best be put down by education,- the way to make people do a thing was to say they should not do it.- (Hear.) He trusted that there would be a better meeting next year.

\section{Dr. Ward then read the following}

\section{REPORT OF THE COUNCIL.}

The council of the Shropshire and North Wales Branch of the Provincial Medical and Surgical Association, at the fourth re-union of its members, have the satisfaction of declaring to them that the society continues to flourish; and that as far as opportunities have been afforded to them, they have endeavoured to carry out the objects of the institution.

On the present occasion, however, in consequence of the importance of the subjects embraced in the report that is about to be laid before the ensuing general meeting at York, it has been deemed advisable to notice local topics only as far as they are connected with the matters alluded to, in order that the merits of these may be thoroughly canvassed and understood before their final adoption.

The council, therefore, have much pleasure in announcing that a want which has been long felt, of some more speedy mode of communitation be- 